\title{
Efficient Resource Utilization in Information Security Risk Management Investment
}

\author{
Mitende Nicholus Nyapete \\ School of Informatics and \\ Innovative Systems \\ Jaramogi Oginga Odinga \\ University of Science and \\ Technology \\ Bondo Town, Kenya
}

\author{
Prof. Anthony Rodrigues \\ School of Informatics and \\ Innovative Systems \\ Jaramogi Oginga Odinga \\ University of Science and \\ Technology \\ Bondo Town, Kenya
}

\author{
Dr. Samuel Liyala \\ School of Informatics and \\ Innovative Systems \\ Jaramogi Oginga Odinga \\ University of Science and \\ Technology \\ Bondo Town, Kenya
}

\begin{abstract}
Efficient Resource Utilization in Information Security Risk Management Investment can improve organization resiliency to information security threats through identifying key information assets and security risks so that information security expenditures can be directed cost effectively. The purpose of this study is to determine if framing and evaluation components of prospect theory informs information security investment decisions. An empirical study was conducted on six microfinance enterprises using Cochran's correctional formula. Mediation Regression Analysis (MRA) was used to determine the impact of organization and human factors on efficient information security risk management investment. The study established that Rational Choice Decision Models (RCDM) in the context of information security investment needs to be supplemented with risk perception measurement and account for individual level decision biases.
\end{abstract}

Key: Information Security Risk Management Investment, Rational Choice Decision Models, Information security, Prospect Theory, Information Security, Efficient

\subsection{Introduction:}

Poor Information Technology (IT) investments results to major Information Security (IS) breaches, which translate to both financial and non-financial loss. [15], point out that in 2014 globally business incurred $\$ 23$ trillion loss due to Information Security (breaches). To protect against IS losses business enterprises are investing in proactive measures, through adoption of standard Information Security Risk Management (ISRM) approach. Although the standard ISRM approach provide formal methods for identification and analysis of IS risks, and provide an assessment of potential impacts of IS risk on the business. The standard ISRM approach does not take into consideration the influence of organization factors and decision maker perception on ISRM investment process.

(ISRM) is the process of recognizing IT related threats, determining their consequences on the organization resources, and applying modifying factors in a cost-effective manner to keep adverse consequences within boundary [22]. [31] Explain that effective ISRM program should have a comprehensive view of IS as through applying appropriate policy, training, technology to enhance the integrity of information, accountability and compliance with existing legal frameworks. It should manage organization risk posture proactively, and assist management to identify, manage and optimize risk [1]. [9], point out that effective ISRM help business in refreshing IT risk inventory and assist in the creation of strategies to mitigate and define risk tolerance.

\subsection{Information Security Risk Management Investment (ISRM investment)}

The negative impacts of IS breaches is an issue of major concern. [27] Argue that for organization to derive value from ISRM Investment, they should implement well defined security procedures that protect the right assets. Researchers such as [7] considers returns on ISRM investment as a critical determinant of efficient ISRM, [19] concurs by pointing out that ability of an enterprise to mitigate IT risks depend on how they effectively invest on ISRM processes. Therefore for effective ISRM the management should perform thorough evaluation of investment options. Management should not view ISRM investment as technical problem but, as part of business and risk management strategies [26].

\subsection{Organization factors influencing Information Security Risk Management. \\ Organization factors influencing information security risk management include:}

\subsection{Organization Culture}

Organization Culture refers to a set of shared values, beliefs, assumptions, and practices that shapes and direct members attitudes and behaviors in the organization. [31] Observe that organization culture is a key influencer of ISRM investment. They argue that it is extremely challenging to realize quality ISRM if management and staffs does not support and believe in ISRM investment as priority. [10] Establish that organization culture influences the quality of knowledge and training on ISRM among organization staffs. [3] Concur by 
opining that despite best standard ISRM approach and guidelines, without well supportive organization culture, efficient ISRM investment cannot be realized. Since poor organization cultures do result to deficient security policy and safe guard's implementation [32]. For organization to realize efficient ISRM investment there is need for positive organization culture that support and prioritize ISRM.

\subsection{Alignment to Business Strategy}

The alignment of ISRM to business strategy is a critical element of efficient ISRM investment. [2]. [19], point out that for achievement of business strategic goal, ISRM should be in tandem with strategic goal. [17] Argue that ISRM investment can only improve enterprise performance and image only if it matches business processes and also supported by business structures and processes. They established that despite significance investment, most organization have not been able to realize full benefits of ISRM investment due to their own inability to effectively align ISRM to business strategy [6].

\subsection{Investment Valuation and Trade-off}

ISRM investment constitutes larger portion of organization expenses, therefore managers should have quality knowledge on ISRM investment valuation and trade-off [21]. [5], point out that valuation and trade-off of ISRM investment is challenging as it is characterized by long payback period, uncertainty, and constantly changing business environment. They established that the widely used RCDM are not suited for ISRM investment since it does not account for the flexibility inherent in most ISRM investment decisions. [28] Observe that defining criterion for evaluation and trade-off of ISRM investment is a nightmare to managers. [29], pointed out that returns on ISRM investment cannot be measured quantitatively and therefore should not be considered in the same footing as other investments. [31], argue that the availability of wide spectrum of ISRM approaches and absence of quality ISRM investment decision making methods makes it absolute difficult for managers to perform effective valuation and trade-off in the context of ISRM.

\subsection{Stakeholder Participation}

Success in ISRM investment is dependent on collective effort of both internal and external stakeholders [25] .Therefore for efficiency in ISRM investment; there is need for ISRM investment plan that is developed with participation of all stakeholders [31]. But in contrary, [32], established that most organization management do not involve key stakeholders in ISRM investment decisions, but, instead keep secret losses that emanates from IS breaches

\subsection{IT Asset Inventory}

IT asset inventory is a set of business processes designed to manage the lifecycle and inventory of technology assets. It provides value to organizations by lowering IT costs, reducing IT risk and improving productivity through proper and predefined asset management. IT asset inventory increases understanding of whom, in the organization needs which IT assets in order to fulfill their assigned roles. A fully functional and well documented IT asset inventory assist business enterprise to identify and map critical assets to risks they are exposed. Lack of well defined asset inventory hinders efficient ISRM investment.

\subsection{Risk Inventories}

Comprehensive risk inventory provide valuable information that assist in enhancing the risk management processes through: enabling the organization to identify gaps in its current risk management processes. As new risks are identified in the risk assessment process, the knowledge gained from a comprehensive inventory help the organization to assess the connections between existing risk management processes and the most critical enterprise level risks so that management can determine if there are any gaps in their risk management process. [19] Point out that risk inventory creates value through assisting organization in mapping risks to underlying objectives.

\subsection{Approaches to Information Security Risk Management Investment (ISRM investment)}

\subsection{The Optimum Information Security Risk Management Investment Approach}

Experts of optimum ISRM investment methods have proposed various strategies to determine the optimum resources for ISRM investment activities. [18], proposed two frameworks; in the first framework they considered the firm's objective to be reduction of losses due felonious. In the second framework they considered firms reputation as the key driver for ISRM investment. [11], developed model which considers the ISRM implementer to be risk impartial when making ISRM investment decision. They pointed out that the expenses incurred in securing organization assets should not exceed $37 \%$ of the expected loss emanating from the occurrence of the security breach. Huang's model Optimum ISRM investments with assumption that the decision makers are risk averse [14]. The model offers core managerial insight into ISRM investment decision. They observe that for successful ISRM investment the organization should carefully evaluate risks impact to business.

[12], model determined the relationship between ISRM investment and vulnerability. The model considers the nature of return as a core determinant of ISRM investment. [30], developed probability based model to determine the chance of attacks and the amount of resources to be committed in protecting the asset with the support of API and OSI algorithm. [20] Criticized Gordon and Loeb model for being based on a single decision variable. [24], argues the weakness of Gordon and Loeb model of not taking into consideration the dynamism prospects such as changing value of money and proposed real option theory for the achievement of Optimum ISRM investment. In their study, [8], proposed a model based on game theory. Cavusoglu game theory approach is based on the assertion that both the organization and the attacker are well aware of the vulnerabilities to be exploited. [8], model is more objective when ISRM investment challenge integrates both targeted and random attack. [4], proposed the use of differential game model to analyze ISRM investment decision. [15], proposed utility theoretic model to determine optimum ISRM 
investment. Their investment model has irreversible fixed costs which introduces rigidity into the ISRM investment decision making process.

\subsection{Prospect Theory}

To overcome the RCDM pervasive inconsistencies, [16], developed prospect theory. The prospect is descriptive theory that models real-life choices, rather than optimal decisions. Prospect Theory argues that decision making process involves two steps which are framing and evaluation. Framing helps in the representation of acts, outcomes, identifying framing effect and establishment of reference point. The evaluation phase assists the decision maker to assign value and prioritize various prospects. Framing and evaluation are the key features of prospect theory that distinguishes it from utility theory, and makes it appropriate for efficient resources allocation under risk environment.

In this study prospect theory was adopted to correctly guide framing (presenting) of factors (both organization and human) that influences ISRM investment decisions, determining framing effects in ISRM investment decision making process, create a reference point based on organization wealth on which risk evaluation is determined rather than the final outcomes.

\subsection{Proposed Conceptual Model for Efficient Information Security Risk Management Investment:}

Efficient ISRM investment within business organization can be realized through positive organization culture that prioritize ISRM, by ensuring that management and staff values and appreciate the role of ISRM, have right attitude, knowledge, and has set adequate budget for ISRM Investment [31]. Business strategy is core variable that influences effective ISRM Investment. [17], pointed, that despite significance investments in ISRM a considerable number of firms have not been able to derive full benefits due to their own inability to effectively deploy Information Security Risk Management in their business strategies. For efficient resource utilization, it is prudent for management investment to ensure ISRM is aligned and supported by business strategy. A well documented asset and risk inventory promotes efficient resource utilization in ISRM through correctly identifying organization assets and risks within the organization environment, this assist management to design contingency measures that meets enterprise security objective. Also through asset and risk inventories correct valuations and trade-off can be performed by management.
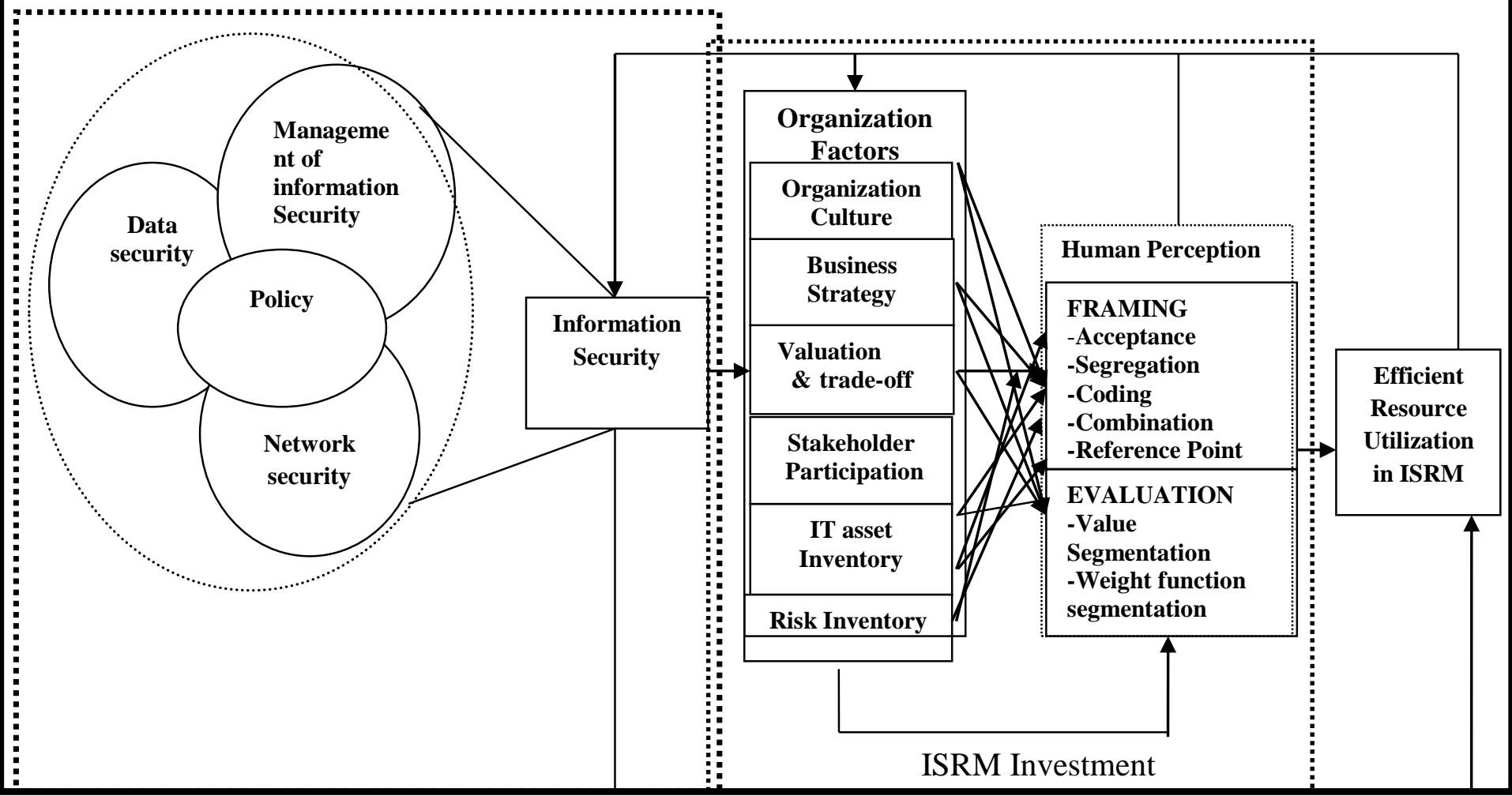

Efficient Resource Utilization Model (Author, 2018)

\subsection{Problem of the study}

Interest in Information Security Risk Management has increased drastically [33]. But, few researchers have focused their energy on the economic implication of Information Security Risk Management. Most of the studies on the economics of Information Security Risk Management emphasize the use of Rational Choice Decision Model to guide Information Security Risk Management Investment. Although Rational Choice Decision Model provides normative guidance concerning investment options, its application in Information Security Risk Management investment context results to two major problems which are: 
(i) Rational choice decision models theorize that individuals calculate the value of each alternative using known probabilities and outcomes. However the probability of occurrence and financial impact resulting from Information Security breaches are rarely known a priori and accurate estimation of these values are highly challenging. Further, accurate estimation of these values is widely recognized as a highly challenging endeavor for even the most experienced practitioner [13]. (ii) The other issue with Rational Choice Decision Model concerns the postulation that Individuals apply probabilities linearly as decision weights. Information security risk management investments are risk related, and researchers have noted that risk related decisions are often characterized by phenomena which violate the fundamental principles of Rational Choice Decision Models. These phenomena include: nonlinear application of probabilities as decision weights and different risk attitudes toward gains and losses.

\subsection{Methodology}

This study adopted descriptive research design to collect ideas and responses from the SMEs employees who are involved in ISRM investment which in turn assisted in coming with efficient information security risk management investment model. The study population was 600 employees out of which 106 respondents were sampled using Cochran's correction formula. A likert structured questionnaire was used to collect the data. The study was conducted among Microfinance SMEs within Nairobi, Kenya. Pilot study was carried out to ensure reliability of data collection instrument. A Cronbach's Alpha value of 0.791 was obtained using SPSS. Correlation analysis was used to establish the relationship between the dependent and independent variables. Mediation Regression Analysis was carried out to establish the influence between the predictors, mediating and the predicted. The outcome of the analysis was a mathematical function to predict the efficient ISRM investment.

\section{0 Results (Mediation Analysis)}

\subsection{Regression Analysis of the Organization Factors and Efficient Resource Utilization}

Model Summary
\begin{tabular}{|l|l|l|l|l|}
\hline Model & R & R Square & $\begin{array}{l}\text { Adjusted } \\
\text { Square }\end{array}$ & $\begin{array}{l}\text { Std. Error of the } \\
\text { Estimate }\end{array}$ \\
\hline 1 & $.633^{\mathrm{a}}$ & .571 & .543 & 2.757 \\
\hline
\end{tabular}

a. Predictors: (Constant), Organization culture, Investment Valuation and Tradeoff, Business Strategy, Stakeholder Participation, IT Risk Inventory, Risk Inventory

ANOVA
\begin{tabular}{|ll|l|l|l|l|l|}
\hline \multicolumn{2}{|l|}{ Model } & Sum of Squares & Df & Mean Square & F & Sig. \\
\hline \multirow{2}{*}{1} & Regression & 503.728 & 6 & 83.955 & 2.424 & $.031^{\mathrm{b}}$ \\
& Residual & 752.687 & 99 & 7.603 & & \\
& Total & 1256.415 & 105 & & & \\
\hline
\end{tabular}

a. Dependent Variable: E.ISRMI

b. Predictors(Constant), Organization culture, Investment Valuation and Trade-off, Business Strategy, Stakeholder Participation, IT Risk Inventory, Risk Inventory 


\begin{tabular}{|c|c|c|c|c|c|c|}
\hline \multirow{2}{*}{\multicolumn{2}{|c|}{ Model }} & \multicolumn{2}{|c|}{ Unstandardized Coefficients } & \multirow{2}{*}{$\begin{array}{l}\text { Standardized } \\
\text { Coefficients } \\
\text { Beta }\end{array}$} & \multirow[t]{2}{*}{$\mathrm{T}$} & \multirow[t]{2}{*}{ Sig. } \\
\hline & & $\mathrm{B}$ & Std. Error & & & \\
\hline \multirow{7}{*}{1} & (Constant) & .803 & .258 & & 3.112 & .000 \\
\hline & Organization Culture & .566 & .292 & .469 & 1.938 & .002 \\
\hline & Investment Valuation and trade-off & .812 & .402 & .322 & 2.019 & .018 \\
\hline & Business Strategy & .617 & .312 & .274 & 1.976 & .024 \\
\hline & Stakeholder Participation & .458 & .214 & .324 & 2.140 & .007 \\
\hline & IT Asset Inventory & .321 & .185 & .269 & 1.735 & .011 \\
\hline & Risk Inventory & .563 & .347 & .275 & 1.622 & .008 \\
\hline
\end{tabular}

a. Dependent Variable: E.ISRMI

$R$ the correlation coefficient shows there was a strong positive relationship between the study variables as shown by $R$ value of 0.633 .Adjusted $R$ squared which is coefficient of determination was 0.543 , an indication that there is variation of $54.3 \%$ efficient resource utilization in ISRM investment due organization factors (organization culture, business strategy, investment valuation and trade-off, stakeholder participation, IT asset inventory and risk inventory) at 95\% confidence interval. The Analysis of Variance (ANOVA) revealed that composite effect of the organization factors on efficient resources utilization in ISRM investment is statistically significance as indicated by the low $P$ values (0.031); that is, less than 0.05 and high $F$ value (2.424), which shows that the overall model was significance. The established Mediation Regression equation was:

$Y=0.803+0.566 \beta 1+0.812 \beta 2+0.617 \beta 3+0.458 \beta 4+0.321 \beta 5+$ $0.563 \beta 6$
The standardized coefficient values shows that variables (organization culture, business strategy, investment valuation and trade-off, stakeholder participation, IT asset inventory and risk inventory) have impact on efficient resources utilization in ISRM investment. This reflected by:

i. Organization Culture $T=1.938 \quad P<\quad .002$ Standardized Coefficient (Beta value) $C=.469$

ii. Investment Valuation, Trade-off $T=3.2 .019 P<$ .018 Standardized Coefficient (Beta value) $C=$ .322

iii. $\quad$ Business Strategy $T=1.976 P<.024$ Standardized Coefficient (Beta value) $C=.274$

iv. Stakeholder Participation $T=2.140 \quad P<.007$ Standardized Coefficient (Beta value) $C=.324$

v. IT Asset inventory $T=1.735 P<.011$ Standardized Coefficient (Beta value) $C=.269$

vi. Risk Inventory $T=1.622 \quad P<.008$ Standardized Coefficient (Beta value) $C=.275$

\subsection{Regression Organization Factors and Efficient Resource Utilization when controlling for Framing and Evaluation}

Model Summary

\begin{tabular}{|l|l|l|l|l|}
\hline Model & R & R Square & Adjusted R Square & $\begin{array}{l}\text { Std. Error of the } \\
\text { Estimate }\end{array}$ \\
\hline 1 & $.723^{\mathrm{a}}$ & .672 & .618 & 2.784 \\
\hline
\end{tabular}

a. Predictors: : (Constant), Organization culture, Investment Valuation and Trade-off, Business Strategy, Stakeholder Participation, IT Risk Inventory, Risk Inventory, Framing, Evaluation 
International Journal of Computer Applications Technology and Research

Volume 7-Issue 02, 86-93, 2018, ISSN:-2319-8656

\section{ANOVA $^{\mathrm{a}}$}

\begin{tabular}{|ll|l|l|l|l|l|}
\hline \multicolumn{2}{|l|}{ Model } & Sum of Squares & Df & Mean Square & F & Sig. \\
\hline \multirow{4}{*}{1} & Regression & 330.372 & 6 & 55.062 & 2.677 & $.018^{\mathrm{b}}$ \\
& Residual & 583.050 & 76 & 7.672 & & \\
& Total & 913.422 & 82 & & & \\
\hline
\end{tabular}

a. Dependent Variable: E.ISRMI

b. Predictors: : (Constant), Organization culture, Investment Valuation and Trade-off, Business Strategy,

Stakeholder Participation, IT Risk Inventory, Risk Inventory, Framing, Evaluation

Coefficients $^{\mathrm{a}}$

\begin{tabular}{|c|c|c|c|c|c|c|}
\hline \multirow{2}{*}{\multicolumn{2}{|c|}{ Model }} & \multicolumn{2}{|c|}{ Unstandardized Coefficients } & \multirow{2}{*}{$\begin{array}{l}\text { Standardized } \\
\text { Coefficients } \\
\text { Beta }\end{array}$} & \multirow[t]{2}{*}{$\mathrm{T}$} & \multirow[t]{2}{*}{ Sig. } \\
\hline & & B & Std. Error & & & \\
\hline \multirow{9}{*}{1} & (Constant) & .494 & .202 & & 2.446 & .000 \\
\hline & Organization culture & .356 & .276 & .029 & 1.289 & .003 \\
\hline & Investment Valuation and Trade-off & .264 & .164 & .047 & 1.609 & .017 \\
\hline & Business Strategy & .481 & .236 & .017 & 2.038 & .024 \\
\hline & Stakeholder Participation & .476 & .217 & .040 & 2.193 & .031 \\
\hline & IT Asset Inventories & .220 & .181 & .031 & 1.215 & .014 \\
\hline & Risk Inventories & .484 & .286 & .032 & 1.681 & .012 \\
\hline & Framing & .205 & .135 & .028 & 1.518 & .021 \\
\hline & Evaluation & .155 & .098 & .029 & 1.581 & .009 \\
\hline
\end{tabular}

a. Dependent Variable: E.ISRMI

The value of adjusted $R$ squared was 0.618 , an indication that there was variation of $61.8 \%$ efficient resource utilization in Information Security Risk Management Investment due to changes in organization culture, investment valuation and trade-off, business strategy, stakeholder participation, IT asset management, risk management, framing, and evaluation at $95 \%$ confidence interval. This shows that $61.8 \%$ changes in efficient resources utilization in Information Security Risk Management investment could be accounted for in organization culture, investment valuation and trade-off, stakeholder participation, IT asset inventory, risk inventory, framing and evaluation. $R$ is the correlation coefficient, which shows the relationship between the study variables and from the findings shown in the appendix9, there was a strong positive relationship between the study variables as shown by $R$ of 0.723 .

The Analysis of Variance (ANOVA) revealed that composite effect of the eight factors organization culture, investment valuation and trade-off, stakeholder participation, IT asset inventory, risk inventory, framing and evaluation on efficient resources utilization in Information
Security Risk Management investment is statistically significance as indicated by the low $P$ values $(0.018)$; that is, less than 0.05 and high $F$ value (2.677), which shows that the overall model was significance.

From the data in the appendix 9 table, the established regression equation was

$Y=0.494+0.356 \beta 1+0.264 \beta 2+0.481 \beta 3+0.476 \beta 4+0.225669$ $0 \beta 5+0.484 \beta 6+0.205 \beta 7+0.155 \beta 8$

The variable organization culture, investment valuation and trade-off, stakeholder participation, IT asset inventory, risk inventory, framing and evaluation have a relationship with efficient resource utilization in Information Security Risk Management as shown below.

i. Organization Culture $T=1.289 \quad P<\quad .003$ Standardized Coefficient (Beta value) $C=.113$

ii. Investment Valuation and Trade-off $T=1.609$ $P<.017$ Standardized Coefficient (Beta value) $C=$ .033

iii. Business Strategy $T=2.038 P<.024$ Standardized Coefficient (Beta Value) $C=.009$ 
iv. Stakeholder Participation $T=2.193 \quad P<.031$ Standardized Coefficient (Beta value) $C=.094$

v. IT Asset inventory $T=1.215 P<.041$ Stadardized Coefficient (Beta value) $C=.116$

vi. Risk Inventory $T=1.681 \quad P<.012$ Standardized Coefficient (Beta value) $C=.046$

vii. Framing $\quad T=1.518 \quad P<.021 \quad$ Standardized Coefficient (Beta value) $C=.077$

viii. Evaluation $T=1.581 \quad P<.009 \quad$ Standardize Coefficient (Beta value) $C=.214$

At the introduction of mediation variable Prospect (framing and evaluation), the standardized coefficient of the regression equation reduces as below:

i. Organization Culture: Standardized Coefficient (Beta value) $C=.469 \quad$ to $C^{1}=.029$

ii. Investment Valuation and trade-off: Standardized Coefficient (Beta value) $\mathrm{C}=.322$ to $\mathrm{C}^{1}=.047$

iii. Business Strategy: Standardized Coefficient (Beta Value) $C=.274$ to $C^{l}=.017$

iv. Stakeholder Participation: Standardized Coefficient (Beta value) $C=.324$ to $C^{l}=.040$

v. IT Asset inventory: Standardized Coefficient (Beta value) $C=.269$ to $C^{l}=.031$

vi. Risk Inventory: Standardized Coefficient (Beta value) $C=.275$ to $C^{l}=.032$

vii. Framing: Standardized Coefficient (Beta) $C=.077$ to $C^{l}=.028$

viii. Evaluation: Standardized Coefficient (Beta) $C=.214$ to $C^{1}=.029$

$\mathrm{Y}=0.618+0.029 \beta 1+0.047 \beta 2+0.017 \beta 3+0.040 \beta 4+0.031 \beta 5+0$. $028 \beta 6+0.029 \beta 7$

The adjusted $\mathrm{R}$ square Coefficient shows a positive variation from $54.6 \%$ to $61.8 \%$ at the introduction of human factors (framing and evaluation)

The reduction in the values of standardized coefficients of the independent variable shows that, Partial mediation exists between the independent variable organization culture, investment valuation, business tradeoff, risk and asset inventories, stakeholder participation and dependent variable ( efficient resources utilization in information security risk management investment), when we control for prospect (framing and evaluation). Also the positive variation experienced in the value of Adjusted $R$ square proves that partial mediation exists between the component of independent variables and dependent variables.

\section{Recommendation}

The study recommends' that for efficient ISRM investment among business enterprises, there is need to implement positive organization culture that is in congruent with organization business strategy and supported by organization structure. The organization staffs at various levels of the organization from operation to senior management level should be trained to support information security risk management. This study recommendation are in tandem with [31] who established that it is extremely difficult to realize quality information security if management does not support and believe in information security risk management invest as a priority.
For efficient ISRM investment, the study recommends the need to have well documented and up to date IT assets and risks inventories as this will assist the SMEs organization to identify critical assets and risks they are exposed and plan for effective information security investments towards their protection. [29] Concur with this recommendation by pointing out that well documented asset and risk inventories can assist the organization to identify the expertise it need, help organization to map critical assets and risks they are exposed.

\section{Reference:}

[1] Al-Jaghoub, S., Al-Yaseen, H., \& Al-Hourani, M. (2010). Evaluation of Awareness and Acceptability of Using e-. Government Services in Developing Countries: the Case of Jordan. The Electronic Journal Information Systems Evaluation, 13(1), 1-8.

[2] Ariyachandra, T. R., \& Frolick, M. N. (2008). Critical Success Factors in Business Performance ManagementStriving for Success. Information Systems Management, 25(2), 113-120.

[3] Baker, W., \& Wallace, L. (2007). Is Information Security Under Control?: Investigating Quality in Information Security Management. IEEE Security and Privacy Magazine, 5(1), 36-44. https://doi.org/10.1109/MSP.2007.11

[4] Bandyopadhyay, T., Liu, D., Mookerjee, V. S., \& Wilhite, A. W. (2014). Dynamic competition in IT security: A differential games approach. Information Systems Frontiers, 16(4), 643-661.

[5] Bardhan, I. R., Bagchi, S., \& Sougstad, R. (2004). Prioritizing a portfolio of information technology investment projects. Journal of Management Information Systems, 21(2), 33-60.

[6] Bleistein, S. J., Cox, K., Verner, J., \& Phalp, K. T. (2006). B-SCP: A requirements analysis framework for validating strategic alignment of organizational IT based on strategycontext, and process. Information and Software Technology, 48(9), 846-868.

[7] Brink, D. (2001). "A guide to determining return on investment for e-security." RSA Security Inc.

[8] Cavusoglu, H., Raghunathan, S., \& Yue, W. T. (2008). Decision-Theoretic and Game-Theoretic Approaches to IT Security Investment. Journal of Management Information Systems, 25(2), 281-304.

[9] Ciorciari, M., \& Blattner, P. (2008). Enterprise risk management maturity-level assessment tool (pp. 1-3). Retrievedfromhttps://www.soa.org/...monographs/2008...sy mposium/mono 2008-m-as08-1-ciorciari.

[10] Fenz, S., Ekelhar, A., \& Neubaue, T. (2011). Information Security Risk Management: In which Security Solutions is it worth Investing? Communications of the Association for Information Systems :, 28(1), 329-356.

[11] Gordon, L. A., \& Loeb, M. P. (2002). The economics of information security investment. ACM Transactions on Information and System Security, 5(4), 438-457. https://doi.org/10.1145/581271.581274

[12] Hausken, K. (2007). Returns to information security investment: The effect of alternative information security breach functions on optimal investment and sensitivity to vulnerability. Information Systems Frontiers, 8(5), 338-349. https://doi.org/10.1007/s10796-006-9011-6 
[13] Home land security. (2009). A roadmap for cyber security research (pp. 1-126). Washington: INFOSEC Research Council (IRC).

[14] Huang, C. D., Hu, Q., \& Behara, R. S. (2008). An economic analysis of the optimal information security investment in the case of a risk-averse firm. International Journal of Production Economics, 2(114), 793-804.

[15] Ioannidis, C., Pym, D., \& Williams, J. (2013). Fixed Costs, Investment Rigidities, and Risk Aversion in Information Security: A Utility-theoretic Approach. In B. Schneier (Ed.), Economics of Information Security and Privacy III (pp. 171-191). New York, NY: $\quad$ Springer New York.

[16] Kahneman, D., \& Tversky, A. (1979). The simulation heuristic. In D. Kahneman, P. Slovic, \& A. Tversky

(Eds.), Judgment under uncertainty: Heuristics and biases (pp. 201-208). New York: Cambridge University Press.

[17] Karim, J., Somers, T., \& Bhattacherjee, A. (2007). The impact of ERP implementation on business process outcomes: a factor-based study. Journal of Management Information Systems, 24(1), 101-134. https://doi.org/10.2753/MIS0742-1222240103

[18] Kort, P. M., Haunschmied, J. L., \& Feichtinger, G. (1999). Optimal firm investment in security. Annals of Operations Research, 88(0), 81-98.

[19] Magnusson, C., Molvidsson, J., \& Zetterqvist, S. (2007). Value creation and return on security investments (ROSI). In New Approaches for Security, Privacy and Trust in Complex Environments (pp. 25-35). Springer, Boston.

[20] Matsuura, K. (2003). Information security and economics in computer networks: an interdisciplinary survey and a proposal of integrated optimization of investment. Computing in Economics and Finance (48), 113.

[21] Mithas, S., Tafti, A., Bardan, I., \& Goh, J. M. (2012). Information Technology and Firm Profitability: Mechanisms and Empirical Evidence. MIS Quarterly, 36(1), 205-224.

[22] Nazımoğlu, Ö., \& Özsen, Y. (2010). Analysis of risk dynamics in information technology service delivery. Journal of Enterprise Information Management, 23(3), 350 364.

[23] Price water Coopers.(2015). 2014 annual report of Price Water Coopers. Retrieved from https://www.pwc.com/gx/en/about-pwc/global-annualreview-2015/campaign-site/pwc-global-annual-review2015.pdf

[24] Tatsumi K., Goto M. (2009) Optimal Timing of Information Security Investment: A Real Options Approach. In: Moore T., Pym D., Ioannidis C. (eds) Economics of Information Security and Privacy (pp 211 - 228). Boston: Springer

[25] Trkman, P. (2010). "The critical success factors of business process management. International Journal of Information Management, 30 (2010), 125-134.

[26] Tsiakis, T., Kargidis, T., \& Katsaros, P. (Eds.). (2014). Approaches and processes for managing the economics of information systems. Hershey, Pa: Business Science Reference.

[27] Tsiakis, T., \& Stephanides, G. (2005). The economic approach of information security. Computers \& Security, 24(2), 105-108. https://doi.org/10.1016/j.cose.2005.02.001
[28] Tsiakis, T., \& Pekos, G. (Eds.). (2008). Analyzing and determining return on investment for information security: proceedings of the 2006 International Conference on Applied Economics (ICOAE). Cham: Springer.

[29] Tsiakis, T. K., \& Pekos, G. D. (2008). Analysing and determining Return on Investment for Information Security. In International Conference on Applied Economics - ICOAE 2008 (pp. 879-883). Thessaloniki: University of Macedonia.

[30] Wang, J., Chaudhury, A., and Rao, H.R. (2008). "A Value-At-Risk Approach to Information Security Investment," Information Systems Research 19(1), 106-120. [31] Whitman, M. E., \& Mattord, H. J. (2013). Management of information security (Fourth edition). Stamford: Cengage Learning.

[32]Wood, C. C., \& Parker, D. B. (2008). "Why ROI and similar financial tools are not advisable for evaluating the merits of security projects." Computer Fraud \& Security, 2004(5), 8-10.

[33] Zafar, H., \& Clark, J. G. (2009). Current stateof information security research in IS. Communications of the Association for Information Systems, 24, 571-596. 